\title{
Maternal attachment and breastfeeding behaviors according to type of delivery in the immediate postpartum period
}

\author{
Nuray Egelioglu Cetisli ${ }^{1 *} \odot$, Gulden Arkan², Ekin Dila Top ${ }^{3}$ \\ ${ }^{1} \mathrm{PhD}$, Assistant Professor, Faculty of Health Sciences, Izmir Katip Celebi University, Izmir, Turkey \\ ${ }^{2}$ RN, Institute of Health Sciences, Izmir Katip Celebi University, Izmir, Turkey \\ ${ }^{3} \mathrm{MsC}, \mathrm{PhD}$ Candidate, Lecturer, Faculty of Health Sciences, Izmir Katip Celebi University, Izmir, Turkey
}

Study conducted at Faculty of Health Sciences, Izmir Katip Celebi University, Izmir, Turkey

Article received: 6/5/2017 Accepted for publication: $7 / 15 / 2017$

*Correspondence: Faculty of Health Sciences Balatcik Campus Izmir Katip Celebi University Izmir - Turkey

Postal code: 35620 nurayegelioglu@gmail.com

\section{SUMMARY}

Introduction: Breastfeeding is nutritious and has physiological benefits regarding the immunological aspect; also, it has an important role on maternal attachment and on raising a healthy baby.

Objective: Our study was conducted to analyze maternal attachment and breastfeeding behaviors in the immediate postpartum period of mothers who had vaginal and cesarean birth.

Method: This descriptive and comparative study was conducted with women who sought the childbirth clinic of a university hospital in Izmir, Turkey. In the study, 175 mothers were attended; 83 of them had vaginal birth and 92 had cesarean birth. Data were collected by using Demographic Identification Form, Maternal Attachment Inventory and LATCH Breastfeeding Assessment Score Tool. Descriptive and correlational statistics were used for data analysis.

Results: We found that Maternal Attachment Inventory and the LATCH breastfeeding charting system of mothers that had vaginal birth was higher than that of mothers who had cesarean delivery. There was a positive correlation between Maternal Attachment Inventory and LATCH total score average for both cesarean and vaginal birth.

Conclusion: Mothers who delivered their babies by cesarean section had problems related to maternal attachment and breastfeeding more often than those who delivered vaginally.

Keywords: Breastfeeding. Cesarean Section. Natural Childbirth. Delivery, Obstetric. Parturition. Mother-Child Relations.

\section{INTRODUCTION}

Early infancy is a special period that shapes the development of human beings. There are four factors related to each other for parents to provide a positive environment for the development of a baby after birth; (1) protection from danger/injury, (2) responsive care, (3) breastfeeding, (4) healthy attachment. ${ }^{1}$ Attachment was first defined in 1950 as "strong connection between two people" by Ainsworth and Bowlby, ${ }^{2}$ who developed the attachment hypothesis. Bowlby defined maternal attachment as "warm, continuous and intimate relation between the mother and the baby. Both sides are delighted and take pleasure in the relationship". Maternal attachment starts with breastfeeding after birth, as the baby turns its attention to the mother, looking for the breast, turning the head, catching, sucking and swallowing. Breastfeeding is one of the most important encouraging factors in maternal attachment. Maternity feeling might develop in a stronger fashion as if the interaction between a mother and her baby is close and healthy. ${ }^{3-5}$

Maternal attachment, meaning a loving connection between the mother and her baby, is one of the most important encouraging factors in healthy infant development. The first attachment experience of the baby is the basis for her/his future attachment experiences. In summary, attachment feelings experienced as dependable or undependable in the newborn period will continue for the whole life. . $^{6-10}$ If dependable attachment necessities between the baby and mother could not be satisfied in the first year, the baby might have emotional, social, physical, men- 
tal and speaking developmental problems. In insufficient maternal attachment conditions, the baby runs the risk of negligence and exploitation. Alhusen et al. ${ }^{11}$ declared in their study that mothers who have higher maternal attachment levels were more sensitive, tender and participating parents, affecting the development of the baby positively in their early infancy period. Schwarze et al. ${ }^{12}$ stated in their study that breastfeeding is important in maternal attachment and less breastfeeding is a risk factor for borderline personality disorder.

The first 60-90 minutes after birth and the motherbaby connection in the first three days of the neonatal period are very important for maternal attachment. In the literature, it was declared that mothers who received their baby just after their vaginal birth exhibit compassionate behavior and hug much more often compared to the ones that had cesarean birth. ${ }^{13-16}$ In the literature, there are reports that the risk of problems and difficulties that might seen in the postpartum period was higher using cesarean section compared with vaginal birth. ${ }^{4-6,10-13}$ However, the rate of cesarean births continues to increase. According to the literature, mothers who were not able to stand up for 6-12 hours after the cesarean birth, who could not have oral feeding after intestine activity starts, who had severe pain or who needed to use a bladder catheter might have difficulties in the first days after the birth. There are reports in the literature that mothers who had cesarean birth showed difficulties in their own self-care, in carrying on their daily life activities, in assuring the aftercare needs of the newborn, as well as presented breastfeeding problems. ${ }^{3,5,10}$ Delay in maternal attachment is obvious in cesarean birth because of common problems regarding surgery and because of common problems observed in postpartum period. ${ }^{13}$

This study was conducted in the first three days of the newborns' life, which is the most important and the earliest period for maternal attachment. It was conducted to evaluate the maternal attachment and feeding behavior of mothers who delivered their babies vaginally or by cesarean section. Another aim of the study was to analyze the relation between maternal attachment and breastfeeding, which is thought to be effective to trigger maternal attachment in early postpartum period.

\section{Method}

This descriptive and comparative study was conducted with women who attended the childbirth clinic of a university hospital in Izmir, Turkey from July 15, 2014 to May 30, 2015. In the study, 175 mothers were attended, 83 of them had vaginal birth and 92 delivered their babies via cesarean section. Mothers who (1) were primipara, (2) had been born mature ( $\geq 38^{\text {th }}$ week), (3) did not have risky pregnancy and had not had risky birth, (4) were literate and (5) were willing to participate in the study.

Data were collected using the Demographic Identification Form, the Maternal Attachment Inventory (MAI) developed by Muller (1994) and validated by Kavlak and Sirin, ${ }^{15}$ and the LATCH Breastfeeding Assessment Score Tool validated by Yenal and Okumus ${ }^{16}$ in Turkish.

\section{Demographic Identification Form}

This form was developed by a review of the literature. $4,5,10,11,13$ It consisted of 12 questions adapted to determine the mother's sociodemographic characteristics (age, education, income, and employment status) as well as information on breastfeeding behavior.

\section{Maternal Attachment Inventory (MAI)}

This measurement tool was developed by Mary E. Muller in 1994. The validation of it was done by Kavlak and Sirin in 2009 and the Cronbach alpha value found was 0.77 . Because it was applied by the participant herself to measure maternal feelings and behaviors representing love, this scale is applicable only for literate women. The scale consists of 26 items with four Likert type answers ranging from "always" to "never." Each item involved direct statements with the following scores for the answers: always, 4 points; frequently, 3 points; sometimes, 2 points; and never, 1 point. A general score is calculated by summing up the scores of each item. A high total score shows that maternal attachment is high. The lowest score is 26 and the highest score is $104 .{ }^{15}$ The Cronbach alpha value for this study was 0.94 .

\section{LATCH Breastfeeding Assessment Score Tool}

LATCH is one of the measuring tools to evaluate breastfeeding and is represented as a visual scale similar to that of the Apgar system. This measurement tool has five evaluation criteria as follows:

- L: Latch on breast.

- A: Audible swallowing.

- T: Type of nipple.

- C: Comfort breast/nipple.

- H: Hold.

The validation study of the LATCH Breastfeeding Assessment Score Tool was performed in 1997 by Adams and Hewell in the USA. In Turkey, the validation study was performed by Yenal and Okumus in 2003 and the Cronbach's alpha value was determined as 0.95 . Each statement evaluated scored between 0-2 points, so that 
the total score obtained with the scale is 10 . Higher scores show that the breastfeeding assessment is better. ${ }^{16}$ In our study the Cronbach's alpha value was 0.89 .

Official permission was given by the clinical research ethics committee of the hospital where the study was conducted (Date: 03.07.2014, Number: 2014-131). Participants were informed about the purpose of the research and gave their written permission before data were collected.

In our study, a face-to-face structured interview with each mother was conducted by the researchers $48-72$ hours after the birth. The time allocated for a woman to complete the questionnaires was approximately $15-20$ minutes. All the data were analyzed using SPSS version 21.0 for Windows. The sociodemographic characteristics of women participating in the study were reported as number and percentage distribution. To analyze the average score of the Maternal Attachment Inventory and the average score of LATCH Breastfeeding Assessment Score Tool, confirmation of normal distribution was obtained, and parametric (variance analyze, independent sample t-test) and non-parametric tests (Mann-Whitney U and Kruskal-Wallis) were performed. Correlation analysis was used to determine the relationship between the Maternal Attachment Inventory and LATCH Breastfeeding Assessment Score Tool. p-values $<.05$ were accepted as statistically significant.

\section{Results}

Sociodemographic characteristics of participants are displayed in Table 1. In this study, 175 mothers were included; 83 had vaginal birth and 92 had cesarean birth. The average age of mothers who had vaginal birth was 23.59 years, $67.5 \%$ of them had completed primary school, $90.4 \%$ were unemployed, $60.2 \%$ had middle-class income, $48.2 \%$ had knowledge about the postpartum period and $55.4 \%$ had a female baby. On the other hand, the average age of mothers who had cesarean birth was 24.92 years, $59.8 \%$ of them had completed primary school, $89.1 \%$ were unemployed, $58.7 \%$ had middle-class income, $60.2 \%$ had knowledge about the postpartum period, and $51.1 \%$ of them had a female baby. There were no significant differences between the mothers that had vaginal and cesarean birth in terms of age $(F=3.608, p=0.059)$, education $\left(x^{2}=1.190, p=0.551\right)$, employment status $\left(x^{2}=0.072\right.$, $\mathrm{p}=0.789)$, income level $\left(\mathrm{x}^{2}=0.043, \mathrm{p}=0.835\right)$, gender of baby $\left(x^{2}=0.741, \mathrm{p}^{=0.389}\right)$ and having knowledge about postpartum period $\left(\mathrm{x}^{2}=3.346, \mathrm{p}=0.067\right)$ (Table 1 ).

In our study, MAI score average of mothers who had vaginal birth was $97.07 \pm 7.01$ points, while the score of the mothers who had cesarean birth was $91.86 \pm 14.11$ points. The difference was statistically significant $(\mathrm{F}=9.193$, $\mathrm{p}=0.003)$. As for LATCH score average, mothers who had vaginal birth scored $7.83 \pm 1.88$, while those who underwent cesarean section scored $7.04 \pm 2.31$ points. Again, the difference between them was statistically significant $(\mathrm{F}=6.027$, $\mathrm{p}=0.015$ ). There is a positive significant relation between the MAI score average and LATCH total score average for both vaginal birth $(\mathrm{r}=0.675, \mathrm{p}=0.000)$ and cesarean birth $(\mathrm{r}=0.376, \mathrm{p}=0.000)($ Table 2) (Figure 1) (Figure 2).

\section{Discussion}

Attachment is a behavioral pattern showing the emotional relationship between the mother and her baby. There are different results in the literature regarding the studies conducted to analyze the effect of birth type on the mother-baby interaction. Contrary to our findings, some studies reported that there is no relation between maternal attachment and the birth type. ${ }^{17-19}$ Hergüner et al. ${ }^{4}$ conducted a study $(\mathrm{n}=80$, vaginal birth $=40$, cesarean birth $=40)$ to analyze the effect of birth type on depression in the postpartum period, perceived social support and maternal attachment. They used MAI and, similarly to our results, found that MAI score average of mothers who had vaginal birth was higher compared to the ones who had cesarean birth. In vaginal birth, oxytocin released from the posterior pituitary together with spasms of uterus and vaginocervical irritability occur. Oxytocin is a hormone related with maternal behavior. ${ }^{90-23}$ Swain et al. found in their study that cerebral activity increased more in vaginal birth compared to cesarean birth. ${ }^{20}$

Alus Tokat et al. ${ }^{6}$ found in their study, which was conduct to analyze self-sufficiency on breastfeeding and breastfeeding situation in the first 24 hours regarding to the birth type, mothers that had cesarean birth had more breastfeeding problems. Similar to our study, other studies declared also that mothers who had cesarean birth experienced more breastfeeding problems compared to those that had vaginal birth. ${ }^{17,21-24}$ In the study by Zanardo et al., ${ }^{25}$ in which the ratio of breastfeeding was compared in cesarean and normal birth, the authors declared that breastfeeding ratio was lower in cesarean birth. Additionally to common problems seen after the cesarean surgery, inability to have an appropriate position for breastfeeding is another preventive factor to start breastfeeding in the early period. It was thought in this study that the difference on breastfeeding regarding to birth type was resulted because of all these factors. Also differences related to birth type were thought to be the factors affecting nutrition in postpartum early period. In the study by Heidarzadeh et al. ${ }^{26}$ which was conducted to compare breast crawl times regarding birth type, found that babies born via cesarean section crawled 
TABLE 1 Demographic characteristics.

\begin{tabular}{|c|c|c|c|}
\hline & Vaginal birth $(n=83)$ & Cesarean birth $(n=92)$ & Significance \\
\hline Age $^{a}$ (years) & $23.59 \pm 4.53$ & $24.92 \pm 4.72$ & $F=3.608$ \\
\hline (Min-max) & $(18-41)$ & $(19-42)$ & $p=0.059$ \\
\hline \multicolumn{4}{|l|}{ Education ${ }^{\mathrm{b}}$} \\
\hline Primary school & $56(67.5)$ & $55(59.8)$ & \multirow{3}{*}{$\begin{array}{l}x^{2}=1.190 \\
p=0.551\end{array}$} \\
\hline High school & $17(20.5)$ & $22(23.9)$ & \\
\hline University & $10(12.0)$ & $15(16.3)$ & \\
\hline \multicolumn{4}{|l|}{ Employment $^{\mathrm{b}}$} \\
\hline Employed & $8(9.6)$ & $10(10.9)$ & $x^{2}=0.072$ \\
\hline Unemployed & $75(90.4)$ & $82(89.1)$ & $p=0.789$ \\
\hline \multicolumn{4}{|l|}{ Income ${ }^{b}$} \\
\hline Low & $33(39.8)$ & $38(41.3)$ & $x^{2}=0.043$ \\
\hline Moderate & $50(60.2)$ & $54(58.7)$ & $p=0.835$ \\
\hline \multicolumn{4}{|l|}{ Infant sex ${ }^{b}$} \\
\hline Female & $46(55.4)$ & $45(48.9)$ & $x^{2}=0.741$ \\
\hline Male & $37(44.6)$ & $47(51.1)$ & $\mathrm{p}=0.389$ \\
\hline \multicolumn{4}{|c|}{ Had they received on postpartum period?b } \\
\hline Yes & $40(48.2)$ & $57(62.0)$ & $x^{2}=3.346$ \\
\hline No & $43(51.8)$ & $35(38.0)$ & $p=0.067$ \\
\hline
\end{tabular}

Values in parentheses are percentages.

${ }^{a}$ Mean \pm SD is supplied.

${ }^{b}$ Frequencies.

TABLE 2 Maternal Attachment Inventory and LATCH score averages regarding the birth type.

\begin{tabular}{llll} 
& Vaginal birth $\mathbf{( n = 8 3 )}$ & Cesarean birth (n=92) & Significance \\
\hline $\begin{array}{l}\text { Maternal Attachment Inventory } \\
\text { Score Average }\end{array}$ & $97.07 \pm 7.06$ & $91.86 \pm 14.11$ & $\mathrm{~F}=9.193$ \\
\hline LATCH total score average & $7.83 \pm 1.88$ & $7.04 \pm 2.31$ & $\mathrm{p}=0.003$ \\
& & & $\mathrm{~F}=6.027$ \\
\hline Significance & $\mathrm{r}=0.675$ & $\mathrm{r}=0.376$ & $\mathrm{p}=0.015$ \\
& $\mathrm{p}=0.000$ & $\mathrm{p}=0.000$ & \\
& & & \\
\hline
\end{tabular}

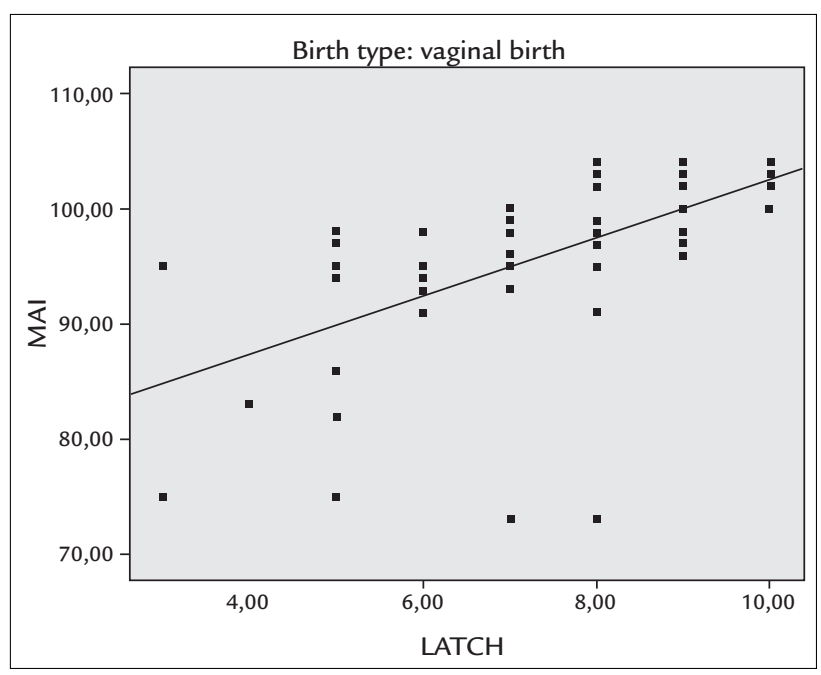

FIGURE 1 The relationship between Maternal Attachment Inventory and LATCH in vaginal birth.

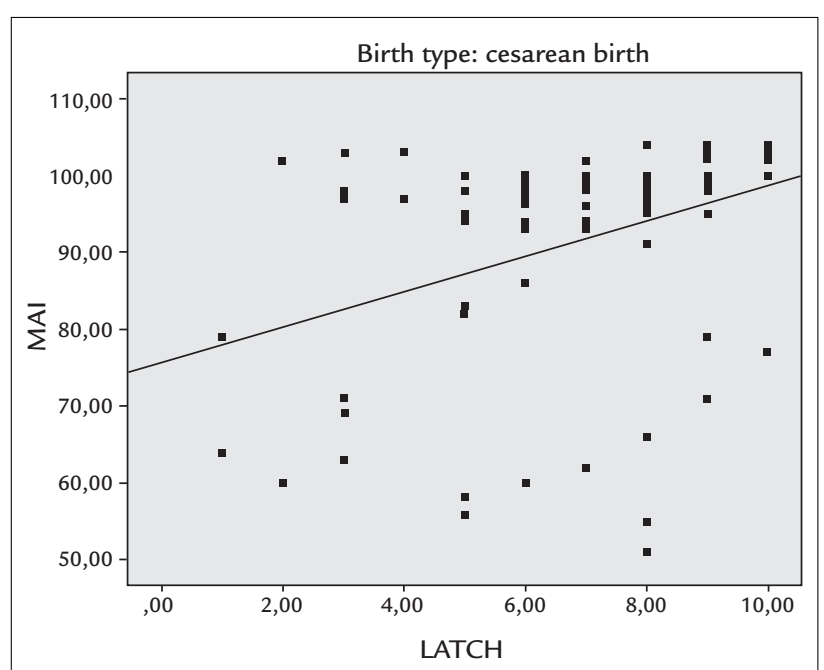

FIGURE 2 The relationship between Maternal Attachment Inventory and LATCH in cesarean birth. 
to the breast in a shorter time compared to babies born vaginally. Nurses who work closely with mother and baby in the early postpartum period should know that differences might be seen during breastfeeding regarding the birth type and they should determine possible problems and plan the care.

In this study, a relation was determined between maternal attachment and breastfeeding behaviors in both vaginal and cesarean birth. Similarly to our findings, a positive relation was found between maternal attachment and breastfeeding and the importance of breastfeeding in the immediate postpartum period is emphasized in the literature. ${ }^{12,27-30}$ In the systematic review by Moore et al., it was determined that newborns that had early skin-to-skin contact cried less and made more physical contact with their mothers. ${ }^{31}$ Also, they stated that maternal attachment was better and the newborns had a tendency to breastfeed more and for longer. Breastfeeding plays an important role on maternal attachment and healthy development of a child in addition to its nutritive and physiological benefits in terms of immunology. In the study by Liu et al., ${ }^{32}$ the authors stated that breastfeeding was an important factor affecting mother-baby attachment, while the internalization of behavior disorders by the child would be related to weak mother-baby attachment. Similarly, in the studies by Alhusen et al. ${ }^{11}$ and Schwarze et al., ${ }^{12}$ the authors stated that psychological problems related to lack of attachment in childhood were observed in babies that were not breastfed at all or were seldom breastfed. Breastfeeding increases maternal attachment and develops a deep and indelible connection with the baby. Nurses play a key role in starting and continuing of breastfeeding in early postpartum period. It has an important effect on maternal attachment. In postpartum services, nurses should plan the care of the mothers based on birth type, implementing it attentively.

\section{Conclusion}

Women develop maternal-infant attachment through feeding and baby-care activities during the postpartum period. Any forces detrimental to mother-infant interaction may delay the development of maternal-infant attachment. More problems and difficulties are experienced in the postpartum period of cesarean birth compared to vaginal birth. As declared in the results section of our study, cesarean birth leads to more frequent problems in maternal attachment and breastfeeding. Thus, healthcare professionals should encourage mothers to deliver their babies vaginally, eventually increasing the current rates of breastfeeding and to start the maternal attachment in the immediate postpartum period. Also, if healthcare professionals support the mother in the postnatal period to prepare them for the act of breastfeeding in a short time, potential problems related to breastfeeding can be recognized earlier.

\section{Conflict of interest}

The authors declare no conflict of interest.

\section{References}

1. Bryanton J, Beck CT. Postnatal parental education for optimizing infant general health and parent-infant relationships. Cochrane Database Syst Rev. 2010; (1):CD004068

2. Ainsworth MS, Bowlby J. An ethological approach to personality development. Am Psychol. 1991; 46(4):333-41.

3. Akyuz A, Kaya T, Şenel N. Determination of breastfeeding behaviors of mothers and influencing factors. TAF Prev Med Bull. 2007; 6(5):331-5.

4. Hergüner S, Çiçek E, Annagür A, Hergüner A, Örs R. Association of delivery type with postpartum depression, perceived social support and maternal attachment. J Psychiatry Neurol Sciences. 2014; 27(1):15-20.

5. Karakaplan S, Yildız H. A study on developing a postpartum comfort questionnaire. Maltepe Üniversitesi Hemşirelik Bilim ve Sanatı Dergisi. 2010; 3(1):55-65.

6. Alus Tokat M, Serçekuş P, Yenal K, Okumuş H. Early postpartum breastfeeding outcomes and breast-feeding self-efficacy in Turkish mothers undergoing vaginal birth or cesarean birth with different types of anesthesia. Int J Nurs Knowl. 2015; 26(2):73-9.

7. Özer A, Taş F, Ekerbiçer HC. Knowledge and behavior of the mothers having 0-6 month old babies about the breast milk and breast feeding. TAF Prev Med Bull. 2010; 9(4):315-20.

8. Sabuncuoğlu O, Berkem M. [Relationship between attachment style and depressive symptoms in postpartum women: findings from Turkey]. Turk Psikiyatri Derg. 2006; 17(4):252-8.

9. Scharfe E. Maternal attachment representations and initiation and duration of breastfeeding. J Hum Lact. 2012; 28(2):218-25.

10. Tully PK, Topu LH. Postnatal unit bassinet types when rooming-in after cesarean birth: implications for breastfeeding and infant safety. J Hum Lact. 2012; 28(4):495-505.

11. Alhusen JL, Hayat MJ, Gross D. A longitudinal study of maternal attachment and infant developmental outcomes. Arch Womens Ment Health. 2013; 16(6):521-9.

12. Schwarze CE, Hellhammer DH, Stroehle V, Lieb K, Mobascher A. Lack of breastfeeding: a potential risk factor in the multifactorial genesis of borderline personality disorder and impaired maternal bonding. J Pers Disord. 2015;29(5):610-26.

13. Pınar G, Doğan N, Algıer L, Kaya N, Çakmak F. Factors that affecting mothers' postnatal comfort. Dicle Med J. 2009; 36(3):184-90.

14. Gulesen A, Yildiz D. Investigation of maternal-infant attachment in the early postpartum period with evidence based practice. TAF Prev Med Bull. 2013; 12(2):177-82.

15. Kavlak O, Şirin A. The Turkish version of Maternal Attachment Inventory. J Human Sciences. 2009; 6(1):188-202.

16. Yenal K, Okumuş H. Reliability of LATCH breastfeeding assessment tool. J Educ Res Nursing. 2003; 5(1):38-44.

17. Carlander AK, Edman G, Christensson K, Andolf E, Wiklund I. Contact between mother, child and partner and attitudes towards breastfeeding in relation to mode of delivery. Sex Reprod Healthc. 2010; 1(1):27-34.

18. Figueiredo B, Costa R, Pacheco A, Pais A. Mother-to-infant emotional involvement at birth. Matern Child Health J. 2009; 13(4):539-49.

19. Lai YL, Hung CH, Stocker J, Chan TF, Liu Y. Postpartum fatigue, baby-care activities, and maternal-infant attachment of vaginal and cesarean births following rooming-in. Appl Nurs Res. 2015; 28(2):116-20.

20. Swain JE, Tasgin E, Mayes LC, Feldman R, Constable RT, Leckman JF Maternal brain response to own baby-cry is affected by cesarean section delivery. J Child Psychol Psychiatry. 2008; 49(10):1042-52.

21. Bar G, Sheiner E, Lezerovizt A, Lazer T, Hallak M. Early maternal feeding following caesarean delivery: a prospective randomised study. Acta Obstet Gynecol Scand. 2008; 87(1):68-71. 
22. Akman I, Kuscu MK, Yurdakul Z, Ozdemir N, Solakoğlu M, Orhon L, et al. Breastfeeding duration and postpartum psychological adjustment: role of maternal attachment styles. J Paediatr Child Health. 2008; 44(6):369-73.

23. Dennis CL. Breastfeeding initiation and duration: a 1990-2000 literature review. J Obstet Gynecol Neonatal Nurs. 2002; 31(1):12-32.

24. Cakmak H, Kuguoglu S. Comparison of the breastfeeding patterns of mothers who delivered their babies per vagina via cesarean section: an observational study using the LATCH breastfeeding charting system. Int J Nurs Stud. 2007; 44(7):1128-37.

25. Zanardo V, Svegliado G, Cavallin F, Giustardi A, Cosmi E, Litta P, et al. Elective cesarean delivery: does it have a negative effect on breastfeeding? Birth. 2010; 37(4):275-9.

26. Heidarzadeh M, Hakimi S, Habibelahi A, Mohammadi M, Shahrak SP Comparison of breast crawl between infants delivered by vaginal delivery and cesarean section. Breastfeed Med. 2016.
27. Cinar N, Köse D, Altinkaynak S. The relationship between maternal attachment, perceived social support and breast-feeding sufficiency. J Coll Physicians Surg Pak. 2015; 25(4):271-5.

28. Goyal RC, Banginwar AS, Ziyo F, Toweir AA. Breastfeeding practices: Positioning, attachment (latch-on) and effective suckling: a hospital-based study in Libya. J Family Community Med. 2011; 18(2):74-9.

29. Himani BK, Kumar P. Effect of initiation of breastfeeding within one hour of the delivery on maternal-infant bonding. Nursing Midwifery Res J. 2011; 7(3):99-109.

30. Huang HC, Wang SY, Chen CH. Body image, maternal-fetal attachment, and choice of infant feeding method: a study in Taiwan. Birth. 2004; 31(3):183-8

31. Moore ER, Anderson GC, Bergman N. Early skin-to-skin contact for mothers and their healthy newborn infants. Cochrane Database Syst Rev. 2007; 18(3):CD003519

32. Liu J, Leung P, Yang A. Breastfeeding and active bonding protects against children's internalizing behavior problems. Nutrients. 2013; 6(1):76-89. 